\title{
Soil Moisture-Evapotranspiration Coupling in CMIP5 Models: Relationship with Simulated Climate and Projections ${ }^{\mathscr{O}}$
}

\author{
AleXIS BERG \\ Department of Civil and Environmental Engineering, Princeton University, Princeton, New Jersey \\ JUSTIN SHEFFIELD \\ Department of Geography, University of Southampton, Southampton, United Kingdom
}

(Manuscript received 7 November 2017, in final form 10 March 2018)

\begin{abstract}
Soil moisture-atmosphere coupling is a key process underlying climate variability and change over land. The control of soil moisture (SM) on evapotranspiration (ET) is a necessary condition for soil moisture to feed back onto surface climate. Here we investigate how this control manifests itself across simulations from the CMIP5 ensemble, using correlation analysis focusing on the interannual (summertime) time scale. Analysis of CMIP5 historical simulations indicates significant model diversity in SM-ET coupling in terms of patterns and magnitude. We investigate the relationship of this spread with differences in background simulated climate. Mean precipitation is found to be an important driver of model spread in SM-ET coupling but does not explain all of the differences, presumably because of model differences in the treatment of land hydrology. Compared to observations, some land regions appear consistently biased dry and thus likely overly soil moisture-limited. Because of ET feedbacks on air temperature, differences in SM-ET coupling induce model uncertainties across the CMIP5 ensemble in mean surface temperature and variability. We explore the relationships between model uncertainties in SM-ET coupling and climate projections. In particular over mid-to-high-latitude continental regions of the Northern Hemisphere but also in parts of the tropics, models that are more soil moisture-limited in the present tend to warm more in future projections, because they project less increase in ET and (in midlatitudes) greater increase in incoming solar radiation. Soil moisture-atmosphere processes thus contribute to the relationship observed across models between summertime present-day simulated climate and future warming projections over land.
\end{abstract}

\section{Introduction}

Surface climate over land is influenced by the physical interactions taking place between the land surface and the overlying atmosphere. The land radiative and physical properties, such as albedo and water availability, are impacted by atmospheric conditions; in turn, land surface variations affect the radiative, moisture, heat, and momentum fluxes between the surface and the atmosphere, impacting the overlying atmosphere and eventually regulating local climate. These interactions encompass a

\footnotetext{
Supplemental information related to this paper is available at the Journals Online website: https://doi.org/10.1175/JCLI-D-170757.s1.
}

Corresponding author: Alexis Berg, ab5@princeton.edu broad range of processes and spatiotemporal scales, from local diurnal surface-boundary layer interactions to longerterm continental-scale ecosystem-climate feedbacks.

On time scales from intraseasonal to interannual, soil moisture is the dominant land surface state variable affecting the global atmosphere (Dirmeyer 2011a). By regulating surface water and energy fluxes, soil moisture variations feedback onto near-surface surface climate (e.g., temperature and humidity); these impacts can extend to the boundary layer vertical structure and thermodynamics and lead to feedbacks on cloud cover and precipitation. Numerous studies have demonstrated such impacts, in both models and observations [see Seneviratne et al. (2010) for an extensive review]. A key aspect underlying these processes is the high spatial and temporal variability in soil moisture, which leads to complex feedbacks with the atmosphere (e.g., Guillod et al. 2015). 
Given the complexity of the physical processes involved and the spatial heterogeneity inherent to the land-atmosphere interface, representing land-atmosphere interactions in weather and climate models has been a scientific challenge. Historically, it can be argued that the parameterized representation of land-atmosphere processes in models was initially driven by the necessity to proceed with physically consistent lower-boundary conditions for atmospheric models, in the context of weather and climate modeling; as a result, it may have lacked strong theoretical foundations or observational constraints. The high-spatiotemporal-resolution observations necessary to underpin coupled land-atmosphere model evaluation and development were simply lacking in spatial and temporal coverage. Still to this day, despite advances in remote sensing and in situ measurement capabilities as well as in model-data fusion techniques, our theoretical understanding of land-atmosphere interactions over different spatiotemporal scales arguably remains incomplete (e.g., Findell et al. 2011; Taylor et al. 2012; Guillod et al. 2015; Tuttle and Salvucci 2016), and observational constraints on land-atmosphere coupling remain difficult to establish (Findell et al. 2015).

In this context, it is perhaps unsurprising that climate models exhibit significant uncertainties in simulated soil moisture-atmosphere coupling. For instance, the landmark multimodel experiment of Global Land-Atmosphere Coupling Experiment (GLACE; Koster et al. 2004) showed that while models, on average, point to consistent regional "hotspots" of significant feedback of soil moisture variability on precipitation, they display large differences in the patterns and amplitude of this feedback (Koster et al. 2006). In addition, although modeling studies generally report a positive relationship between soil moisture, evapotranspiration, and precipitation, some models exhibit little or no coupling (Lawrence and Slingo 2005) or a negative feedback in some regions (Cook et al. 2006). More recently, results from the GLACE-CMIP5 experiment (Seneviratne et al. 2013) have also highlighted intermodel differences in terms of the simulated feedback of soil moisture variability on surface climate (Berg et al. 2015, 2017a; Orth and Seneviratne 2017).

Differences in soil moisture-atmosphere coupling are likely to contribute to model uncertainties in simulated climate and projected climate change, in particular over land regions. Numerous studies have highlighted, for instance, the role of model land-atmosphere processes in simulated summertime temperature variability and extremes (Seneviratne et al. 2006; Fischer et al. 2007; Diro et al. 2014; Berg et al. 2014; Lorenz et al. 2016). Results from the GLACE-CMIP5 experiment (Seneviratne et al. 2013) further show, across a subset of participating models, that soil moisture changes play an important role in the simulated land response to global warming, with soil moisture feedbacks modulating regional and continental hydroclimate changes (Berg et al. 2015, 2016; Vogel et al. 2017). Land-atmosphere processes thus represent a source of uncertainty in model simulations and projections, and it appears essential to better understand, across the broader ensemble of currentgeneration models, the links between land-atmosphere coupling and simulated climate in climate models, as well as the implications for model projections of future climate.

In this context, we focus here on investigating model diversity in terms of the so-called terrestrial leg of the coupling (Dirmeyer 2011b). Soil moisture-atmosphere coupling can conceptually be separated into the coupling between soil moisture (SM) and evapotranspiration (ET) on the one hand (the "terrestrial leg"; Dirmeyer 2011b) and between evapotranspiration and precipitation on the other hand (the "atmospheric leg"). SM-ET coupling is a necessary, although not sufficient, condition for the overall SM-atmosphere coupling to take place; in the context of GLACE, Guo et al. (2006) showed that most of the spread in the overall soil moisture-precipitation coupling between models could be linked to differences in the terrestrial leg. Dirmeyer et al. (2006) also highlighted the differences between GLACE models in the functional shape and strength of the relationship between soil wetness and ET. Thus, in this study we focus on further analyzing SM-ET coupling across the whole ensemble of coupled climate models from phase 5 of the Coupled Model Intercomparison Project (CMIP5). Several studies have addressed soil moisture-atmosphere coupling in CMIP5 models (Williams et al. 2012; Taylor et al. 2012; Levine et al. 2016; Herrera-Estrada and Sheffield 2017). Such studies generally endeavor to provide an observational benchmark of land-atmosphere coupling, typically quantified through a specific metric calculated from remote sensing or in situ data, against which models can be evaluated. Other studies have also used CMIP5 models to understand aspects of future changes in soil moisture and land-atmosphere coupling under global warming robustly predicted by models (Dirmeyer et al. 2013a,b; Herrera-Estrada and Sheffield 2017). Here our focus is slightly different; we focus on the terrestrial part of the coupling only, and, because of the uncertainties in soil moisture and surface fluxes observations mentioned above, we do not explicitly seek here to evaluate models against comparable observations. Rather, we aim to document the diversity in SM-ET coupling across all CMIP5 models and explore the relationships between the spread in this coupling and general aspects of the 
simulated climate in these models. In effect, we aim to use the CMIP5 ensemble as a tool to understand the role of SM-ET coupling in climate models, both in terms of their present-day simulated climate and how it affects climate change projections.

\section{Data and methods}

\section{a. CMIP5 output}

We use monthly output from historical and representative concentration pathway 8.5 (RCP8.5; Riahi et al. 2011) simulations from the CMIP5 experiment. We choose the RCP8.5 simulation to maximize the projected changes in the future and the potential differences between models. Data for the historical simulations are analyzed over 1950-2005, and for RCP8.5 over 2071-2100. Because land-atmosphere processes can be expected to be most important in the summer season, when available surface energy is highest (Dirmeyer 2003), we focus on summertime climate in each hemisphere, considering seasonal values over JuneAugust in the Northern Hemisphere and DecemberFebruary in the Southern Hemisphere. To characterize SM-ET coupling, we analyze output of surface (top $10 \mathrm{~cm}$; variable mrsos in the CMIP5 archive) soil moisture and evapotranspiration. We use surface soil moisture because it is more easily comparable across models, when correlated with surface fluxes, than total (column integrated) soil moisture, which reflects differences in soil depths between models. With soil depth differences of several meters between models, SM-ET coupling differences based on total soil moisture would be difficult to interpret, since deeper soil water is less connected to surface fluxes than nearsurface moisture. Note that one could calculate a common, root-zone-like soil moisture variable across models (e.g., soil moisture down to $2 \mathrm{~m}$ ) by using layer-bylayer soil moisture output from the CMIP5 database (Berg et al. 2017b); however, such output are available for fewer models than surface soil moisture, and we chose to favor and maximize model availability in our analysis.

To understand how coupling strength feedbacks on climate more broadly, we also analyze how SM-ET coupling correlates with output from a number of other surface climate variables: temperature, solar radiation, precipitation, and cloud cover. The number of models available differs slightly for different variables and simulations (i.e., historical and RCP8.5). For instance, 48 models are available for historical ET, but only 37 models for surface soil moisture. We use all models available for each variable (using only one ensemble member-"r1" in the CMIP5 archive-when several members are available), and for each pair of variables we consider, we use the maximum number of common models available. Thus, the number of models considered for different combinations of variables might differ slightly; again, given that the number of models available to be included in these correlations is not large, rather than defining one single set of common models we favor including as many models as possible in our analysis. Table S1 in the supplemental material lists all the models used for each variable. Results are robust to subsetting the models to a common ensemble (which would comprise 32 models). Finally, all model output are regridded to a common $2^{\circ} \times 2^{\circ}$ grid before analysis.

\section{b. Coupling metric and analysis of model diversity}

Numerous metrics have been proposed by the landatmosphere community to evaluate different aspects of land-atmosphere coupling in models and/or observations (Santanello et al. 2018), many of them focusing on diurnal time scale processes and thus relying on subdaily data (e.g., Santanello et al. 2009; Findell et al. 2011). Here, to quantify the strength of the terrestrial leg of soil moisture-atmosphere coupling across models and explore its links with simulated climate and projected climate change, we use a simple linear correlation between surface soil moisture and ET (e.g., Dirmeyer et al. 2009) at the interannual time scale (i.e., using summer-mean values). As indicated above, we use surface soil moisture to maximize the number of models available. Positive correlation values indicate that, at the interannual time scale (from one summer to the next), soil moisture variability controls ET variability. This can generally be expected to occur when soil moisture availability is the limiting factor for ET. Conversely, negative values indicate that ET variations drive variations in soil moisture levels, which can be expected to occur in regions where soil moisture is plentiful and the limiting factor for ET becomes atmospheric evaporative demand. In addition, the correlation value quantifies how much of ET interannual variability is explained by soil moisture variations (if the correlation is positive; vice versa if it is negative) - in other words, the tightness of the SM-ET relationship. While this remains a simple, first-order quantification of soil moisture's impact on surface fluxes compared to more sophisticated and shorter time scale metrics (e.g., Gallego-Elvira et al. 2016), it has the advantage of being easily calculable across models and easily interpretable. Moreover, considering seasonal means removes issues associated with the coseasonality of soil moisture and ET, while still reflecting the overall (i.e., seasonally integrated) dependence of ET on soil moisture throughout the whole season. 
Note that previous studies have used different metrics to quantify SM-ET coupling. Dirmeyer (2011b) focused on the sensitivity of ET to SM (i.e., the slope of the regression between ET and SM, instead of the correlation) scaled by a measure of SM variability (e.g., standard deviation), in order to estimate the overall impact on ET variations of soil moisture variability, in absolute terms (i.e., with the same units as ET). We argue that for our purpose here-exploring differences in the strength of SM-ET coupling across models and its implications for model simulations-it is essential that our metric factors in the strength of the relationship between SM and ET. Since our focus is to compare models and not provide an absolute estimate of SM-controlled ET variations, the simple correlation between SM and ET is most relevant as it is controls for differences in ET variability between models and provides an estimate of the share of ET variance, for each model, controlled by SM. To illustrate this, Fig. S1 in the supplemental material shows the relationship between summer-averaged SM and ET over one point in the central Great Plains over 55 years in the historical simulation. Our interpretation implies, for instance, that SM-ET coupling is stronger in MIROC4h (Sakamoto et al. 2012) than in CCSM4 (Gent et al. 2011) (correlation of 0.92 vs 0.67) even though the regression slope scaled by soil moisture variability (Dirmeyer 2011b) would be greater in the latter.

Finally, several methods have been proposed to analyze multimodel uncertainties in a given quantity and their link with other model characteristics, such as the use of empirical orthogonal function analysis across models (e.g., Langenbrunner et al. 2015). Here, to characterize the diversity of models in terms of SM-ET coupling, we simply calculate the mean and standard deviation of this coupling across models. Doing so allows us to quantify the spread over each pixel separately instead of focusing only on the dominant mode of uncertainty. As indicated above, we then also analyze how SM-ET coupling correlates across models with mean and variability from a number of other surface climate variables (e.g., temperature, precipitation, and ET).

\section{Results}

\section{a. Mean SM-ET coupling and model uncertainty}

Figure 1a shows the multimodel mean SM-ET coupling, that is, the interannual correlation between summertime-mean surface soil moisture and ET over the historical period (1950-2005). Results for each model separately are shown in Fig. S2 of the supplemental material. Figure 1a shows that a significant share of ET variance is explained by soil moisture variability (positive correlation values) in the subtropics and midlatitudes. These are drier regions, where ET is soil moisture limited; consequently, ET variations reflect variations in soil moisture availability. Conversely, more negative values indicate regions where ET variations drive soil moisture variations. These are wetter regions, at high latitudes and in the tropics, where soil moisture availability is no longer limiting for ET; ET variability is then driven by evaporative demand. Note that in some models SM-ET coupling is significantly negative (Fig. S2), reflecting ET's influence on soil moisture levels, whereas in other models correlations remain simply close to zero and nonsignificant, and in a few other models positive SM-ET coupling (i.e., soil moisture limitation on ET) extends into those regions. Multimodel mean values are thus lower (in absolute terms) in those regions. Evaporative demand, such as estimated for instance by the Penman-Monteith equation (Scheff and Frierson 2014), is influenced by a number of atmospheric variables. Positive values in Figs. $1 \mathrm{~b}$ and $1 \mathrm{c}$ show that summertime ET is, generally speaking, more temperature limited at higher latitudes, and solar radiation limited at lower latitudes (note that at mid-to-high latitudes in summer, radiation and temperature are not independent, so that in some regions both variables appear significantly correlated with ET). The overlap between negative correlations on these maps with regions of positive SM-ET coupling reflects the fact that in soil moisture-limited regions, ET depends on precipitation, which is itself negatively correlated with incoming solar radiation (Rsds), as cloud cover masks solar radiation; greater ET is then associated with surface evaporative cooling.

Note that Fig. 1a indicates strong SM-ET coupling in desert regions (Sahara and Middle East); however, in such regions soil moisture availability is limited, so that soil moisture variability, and thus the associated ET interannual variability, remains low (Fig. 1d). This explains the difference between Fig. 1a, which indicates strong SM-ET coupling in desert regions, and other SM-ET coupling metrics that factor in soil moisture variability (e.g., Dirmeyer 2011b). More generally, comparing Figs. 1d and 1a shows that interannual variability of ET is generally greater in soil moisture-limited regions, and remains lower in energy-limited regions, in particular tropical latitudes (despite higher mean levels of ET).

Figure 2a shows the model spread in SM-ET coupling, characterized by the standard deviation across models. Figure 2a shows that in soil moisture-limited drier regions, models generally agree on the strong positive 

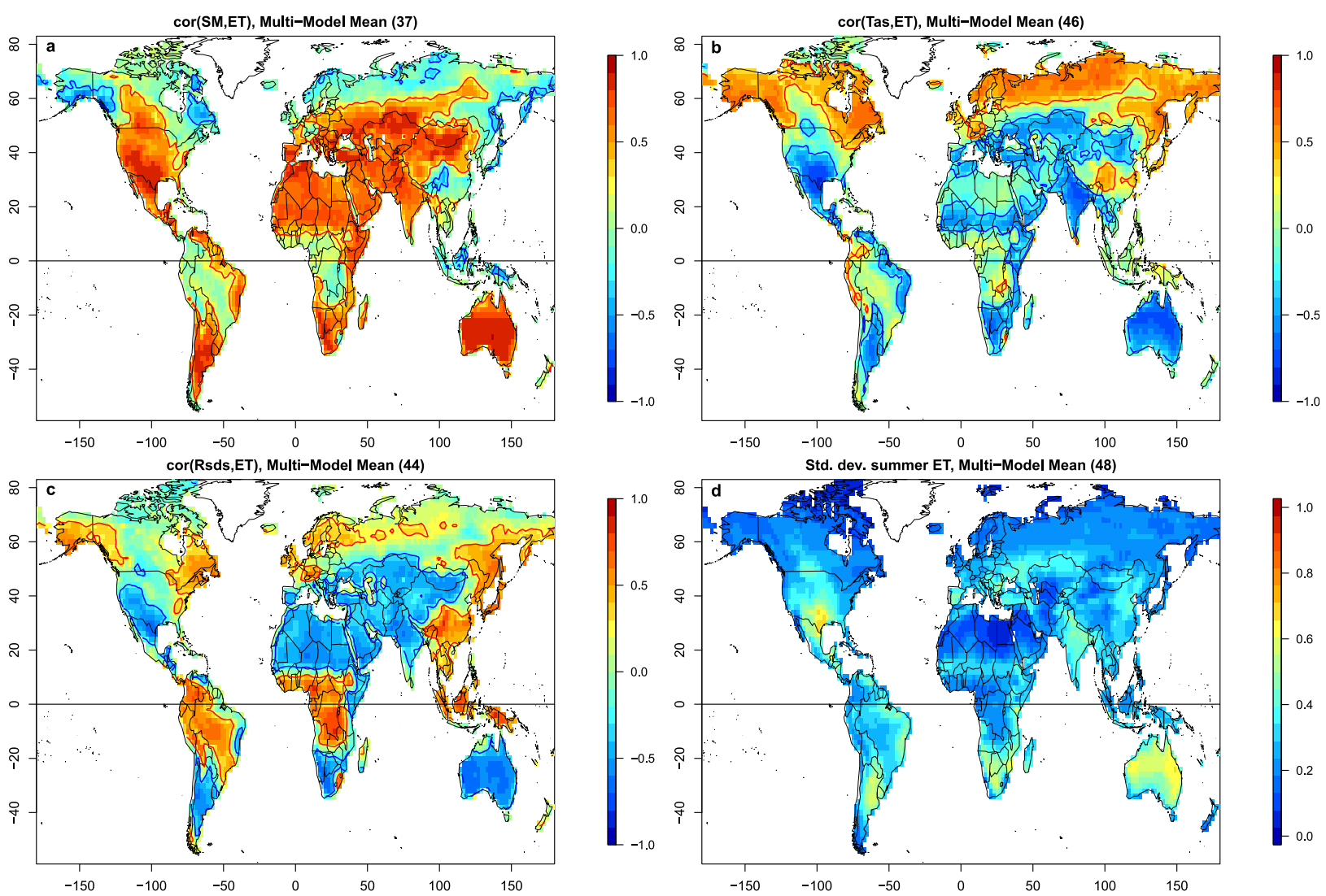

FIG. 1. (a) Multimodel mean correlation between summertime-mean surface SM and ET over 1950-2005; (b) as in (a), but with 2-m temperature (Tas) and ET; (c) as in (a), but with Rsds and ET; and (d) multimodel mean interannual standard deviation of ET (mm day ${ }^{-1}$ ), that is, the interannual standard deviation of (summertime) ET, averaged across all models. The values in parentheses above the panels are the number of models considered in each panel, depending on the availability of model output. Contour lines in (a)-(c) indicate correlations significant at the 5\% level. Values are for June-August in the Northern Hemisphere and for December-February in the Southern Hemisphere.

SM-ET coupling. The only exceptions are over the Sahara and the Middle East where a couple of models (models based on the Hadley Centre land-atmosphere model) show zero correlation (as opposed to strong correlations in all other models); this is because there is no precipitation and ET at all, and thus no SM-ET correlation, in these regions in these models. Thus model spread appears slightly greater in these regions than in other dry regions. Overall, model uncertainty in SM-ET coupling tends to be greatest on the outer margins of regions of positive (from a multimodel mean perspective) coupling, extending into regions of energylimited ET. Figure $2 \mathrm{~b}$ further shows that over most regions-except deserts-SM-ET coupling is anticorrelated with coupling between ET and incoming solar radiation across models. In other words, models that are less moisture limited are more energy limited, and vice versa (similar results are obtained with temperature-ET coupling; not shown). This confirms that the model spread in SM-ET coupling reflects differences across models in the dependence of ET on climatic drivers.

\section{b. Link between coupling spread and mean precipitation}

What explains differences in SM-ET coupling strength across models in Fig. 2? Figure 3a shows that, to a large extent, model differences in SM-ET coupling can be traced back to differences in mean background (summer) precipitation. Intermodel correlations between mean summer precipitation and SM-ET coupling are negative over most of the land surface. This is consistent with results over North America from HerreraEstrada and Sheffield (2017). This reflects the fact that in models with greater (lower) precipitation, ET is less (more) likely to be soil moisture limited. Another contributing factor, in particular in regions that are energy limited (in the multimodel mean sense) is that across the models lower precipitation is generally associated with higher incoming solar radiation (i.e., greater 

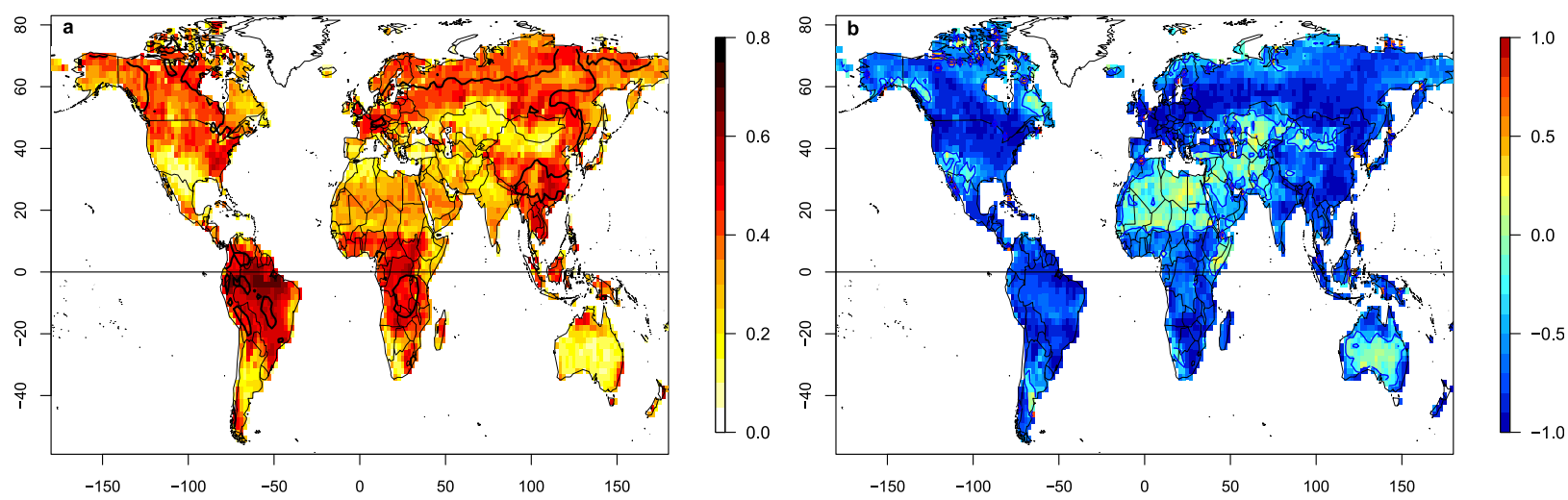

FIG. 2. (a) Standard deviation across 37 CMIP5 models of the correlation between summertime-mean surface SM and ET over 19502005. The black contour indicates where the mean multimodel mean correlation from Fig. 1a is nil. (b) Correlation, across 37 CMIP5 models, between SM-ET correlations and Rsds-ET correlations.

evaporative demand), in which case, all other things being equal, ET is more likely to remain constrained by available soil moisture. Although we cannot rule out a potential contributing role to this negative relationship from soil moisture feedbacks (i.e., that greater SM-ET coupling in a model could, independently, also contribute to lower precipitation, through land-atmosphere feedbacks), the overwhelmingly negative correlation between precipitation and SM-ET coupling suggests it is mainly a result of precipitation forcing. In regions such as the northern United States, the westernmost and easternmost parts of Russia, southern Africa, and the eastern Amazon, mean summer precipitation explains around $50 \%$ or more of intermodel spread in SM-ET coupling. Note that the correlation between precipitation and SM-ET coupling is greater, again not in regions of strongest mean (multimodel) SM-ET coupling but in regions of greater intermodel spread as noted in section 3a. In dry regions (i.e., where soil moisture availability is low enough), most models agree
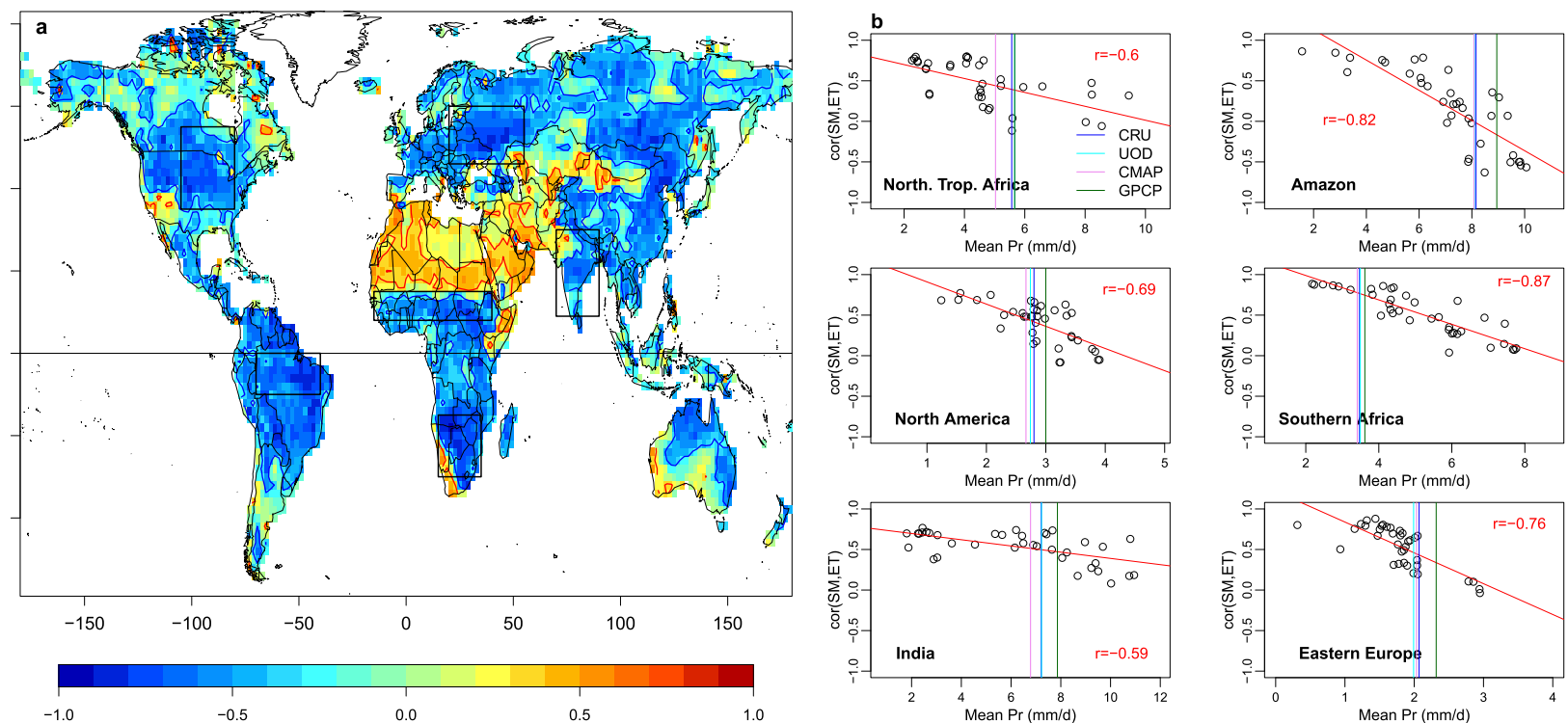

FIG. 3. (a) Correlation across 37 CMIP5 models between mean summertime precipitation and SM-ET coupling; contour lines indicate significant correlations at the $5 \%$ level. (b) For each region delineated by a box in (a), scatterplot of model SM-ET coupling against model mean summertime precipitation. Red lines are regression across all models, with correlation values $r$ given in red. Vertical lines represent observational estimates of mean summer precipitation from different datasets: Climatic Research Unit (CRU) time series (TS) dataset, version 3.21; University of Delaware (UoD) monthly temperature and precipitation dataset, version 3.01; Global Precipitation Climatology Project (GPCP) monthly precipitation dataset, version 2.2; and Climate Prediction Center (CPC) Merged Analysis of Precipitation (CMAP), version 1201. Means are over 1950-2005 for CRU TS and UoD data, 1979-2010 for CMAP, and 1979-2013 for GPCP. 

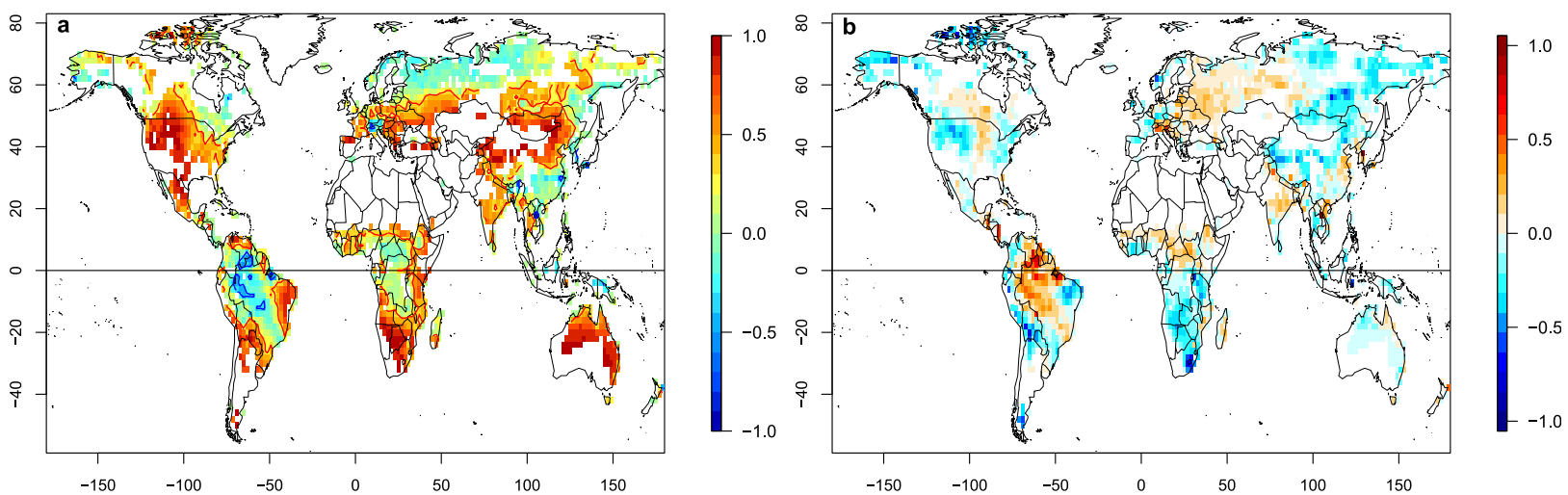

FIG. 4. (a) Estimate of SM-ET coupling based on intersection point of observed CRU TS summertime precipitation over 1950-2005 and intermodel regression line of SM-ET coupling against mean summertime precipitation (Fig. 3b); contour lines indicate correlations significant at the 5\% level. (b) Difference between (a) and multimodel mean SM-ET coupling from Fig. 1a.

that SM-ET coupling is strong regardless of mean precipitation levels (e.g., southern United States and southern Australia). Positive correlations over deserts (Sahara and Middle East) are induced by the few models mentioned above in which precipitation and the associated SM-ET coupling are close to zero.

Figure $3 \mathrm{~b}$ shows scatterplots of model mean summer precipitation against model SM-ET coupling averaged over a subset of regions. This further illustrates how intermodel spread in SM-ET coupling can be explained, to first order, by differences in mean precipitation. This might be partly a result of the simplicity of the correlation metric chosen here to quantify SM-ET coupling, which appears mostly sensitive to precipitation levels. Note however that even with this simple metric, although mean precipitation levels explain a large share of intermodel spread in SM-ET coupling, they do not explain all of it; as Fig. 3b shows, differences in SM-ET coupling are evident for similar levels of precipitation. These may be related to further differences in rainfall characteristics such as the intraseasonal distribution or spring-season precipitation, but they are also likely to result from the different behaviors of different land surface models embedded in the CMIP5 models.

The negative linear relationship in Fig. 3 suggests that any evaluation of SM-ET coupling in climate models should control for model biases in precipitation in the first place. This emerging constraint also suggests a way to provide an observationally constrained estimate of SM-ET coupling in reality. Plotted on Fig. $3 \mathrm{~b}$ are estimates of mean summer precipitation over the different regions. If one assumes that the relationship between mean precipitation and SM-ET coupling depicted by the climate model ensemble reflects a realistic physical dependency, then the intersection of the model regression line with an estimate of observed precipitation
$P$ provides an estimate of SM-ET coupling in reality. The assumption above is equivalent to assuming that models do not share systematic biases in SM-ET coupling (e.g, that all models would be too strongly coupled for a given level of precipitation). Figure 4 a shows such an estimate for every grid point where the correlation between SM-ET coupling and precipitation across models is significant (at the $5 \%$ level). Figure $4 \mathrm{~b}$ then shows the difference between the multimodel mean SM-ET coupling and this $P$-based estimate. In other words, Fig. $4 \mathrm{~b}$ depicts regions of consistent $P$-induced model biases in SM-ET coupling (again assuming that for a given level of $P$, models are not consistently biased in terms of SM-ET coupling one way or another, i.e., that the regression slopes on Fig. 3b are consistent with real-life processes). For instance, South Africa appears as a region where models consistently overestimate summer precipitation, and thus exhibit too weak SM-ET coupling. Conversely, the central Great Plains of North America and western Russia appear as regions of dry multimodel mean bias, with too little precipitation and too strong SM-ET coupling. This is generally consistent with previous evaluations of CMIP5 models in terms of precipitation (e.g., Sheffield et al. 2013) and soil moisture-atmosphere coupling (Herrera-Estrada and Sheffield 2017).

\section{c. SM-ET coupling spread and surface climate}

Similar to Fig. 3a, Fig. 5 shows the correlations across models between SM-ET coupling and mean ET (Fig. 5a) and mean 2-m temperature (Fig. 5b). Models with greater SM-ET coupling tend to show lower mean ET. This, in part, reflects lower mean precipitation in the first place, as suggested by the overlap between Figs. 3a and 5a. Note however that, as indicated above, precipitation levels do not explain all of the spread in SM-ET 

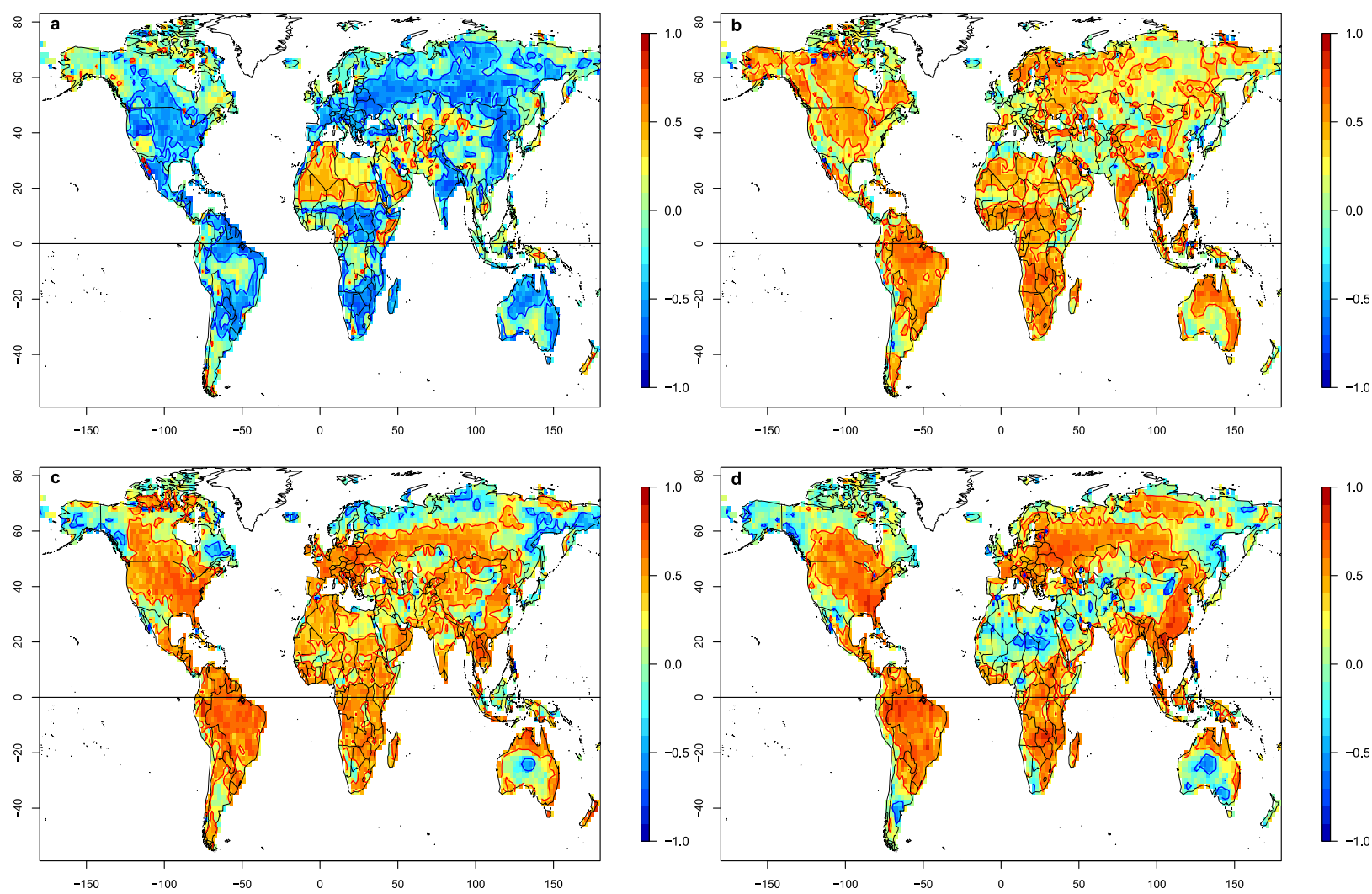

FIG. 5. Correlation across 37 models between SM-ET coupling and, respectively, (a) mean summertime ET, (b) mean summertime 2-m temperature, (c) interannual standard deviation of summertime ET, and (d) interannual standard deviation of summertime 2-m temperature.

coupling: some of the differences in mean ET are thus arguably related to differences in SM-ET coupling independent of differences in precipitation (i.e., by the fact that for a given level of mean precipitation some models are more soil moisture limited than others). The similarity between Figs. 3a and 5a breaks down in tropical land regions, because in these regions ET remains primarily limited by radiation and not by available moisture; even though models with lower precipitation will tend to show more soil moisture control on ET (Fig. 3a), they do not show lower mean ET.

Models with greater SM-ET coupling tend to be warmer (Fig. 5b). In soil moisture-limited regions, greater ET modulates the surface energy budget and leads to lower near-surface temperature. Through its impact on mean ET, SM-ET coupling is thus negatively correlated with mean 2-m temperature across models. Again, we cannot rule out here that higher temperatures in models could, independently of any feedback, also lead to stronger SM-ET coupling, as under higher evaporative demand ET would be more likely to remain more constrained by soil moisture. However, the overlap between Figs. 5a and 5b suggests a dominant role of
ET-mediated feedbacks of soil moisture on temperatures in soil moisture-limited regions. On the other hand, positive correlations between SM-ET coupling and mean temperature also occur over equatorial land regions that are (in a multimodel mean sense) energy limited. SM-ET coupling and mean ET are not correlated in these regions (Fig. 5a). In these regions we interpret the positive correlation between mean temperature and SM-ET coupling across models not as a result of the ET-mediated feedback of SM-ET coupling on temperature, but as a result of the impact of higher evaporative demand, itself induced by higher incoming solar radiation and associated with higher temperature. In these regions, higher evaporative demand likely leads to soil moisture remaining more of a control on ET across the different models. Note that results from Figs. $3 \mathrm{a}$ and $5 \mathrm{~b}$ mean that, across models, mean summertime precipitation and temperature are negatively correlated in soil moisture-limited regions. This negative relationship has been shown at the interannual time scale (e.g., Berg et al. 2015) but also holds here in the mean across models. Biases with respect to temperature observations are consistent with those compared to 


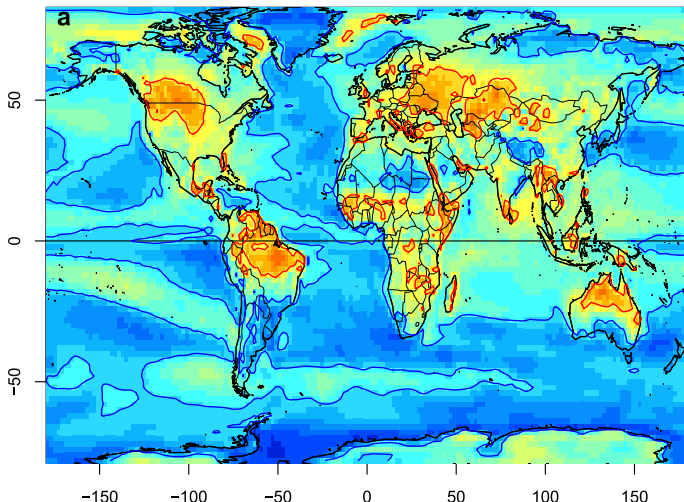

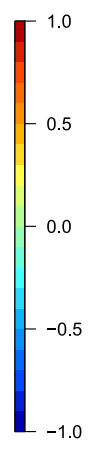

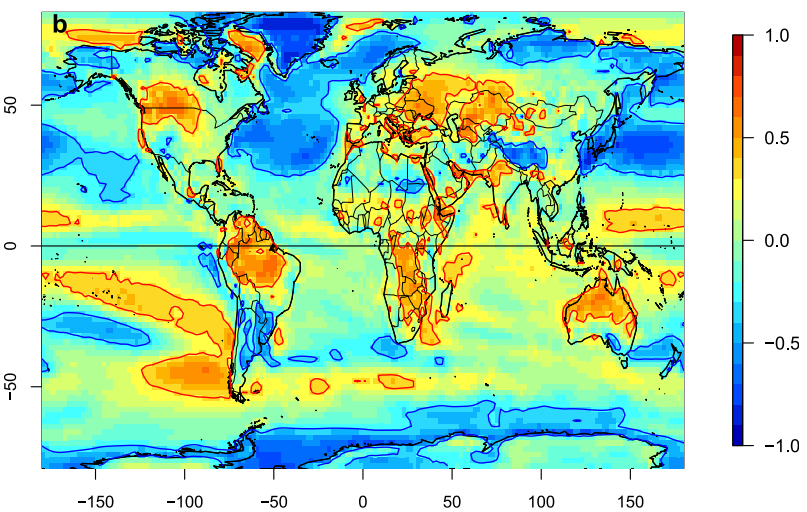

$-150$

FIG. 6. Correlation across 40 models between mean present-day (1950-2005) summertime 2-m temperature and, respectively, (a) projected summertime warming under the RCP8.5 scenario, from present-day to end of twenty-first century (2071-2100) and (b) projected local summertime warming amplification, for each pixel and model defined as future warming over that pixel minus global mean warming for that particular model. Contour lines indicate correlations significant at the $5 \%$ level.

precipitation observations in Fig. 3b (not shown); for instance, regions where most models are too wet, such as southern Africa, are also regions where most models are too cold.

Figures $5 \mathrm{c}$ and $5 \mathrm{~d}$ show that over most of the land surface, greater SM-ET coupling in models is also associated with greater (interannual) variability of ET and temperature $T$. The overlap between Figs. $5 \mathrm{c}$ and $5 \mathrm{~d}$ suggests that the greater $T$ variability in models with greater SM-ET coupling is primarily caused by the enhanced ET variability. This relationship across models highlights the role of soil moisture-atmosphere processes in simulated temperature variability in climate models. This is consistent with a large body of literature on the role of land processes in summertime temperature variability and extremes (e.g., Seneviratne et al. 2006; Fischer et al. 2007; Diro et al. 2014; Berg et al. 2014; Lorenz et al. 2016; Herrera-Estrada and Sheffield 2017). One implication of this relationship is that model biases in different moments of the temperature distribution are not independent across models; that is, because of differences in SM-ET coupling (in part induced by differences in precipitation), models that are warmer on average (in summer) are also models that show greater temperature variability. In fact, model analysis of the role of soil moisture-atmosphere interactions on temperature distribution (Berg et al. 2014) suggests that models with greater SM-ET coupling are warmer on average precisely because of greater temperature variability (i.e., more frequent high-temperature events induced by soil moisture-atmosphere feedbacks).

\section{d. SM-ET coupling and simulated climate change}

In this section we turn to the potential relationship of model spread in SM-ET coupling with uncertainties in simulated climate change projections, considering projected changes by the end of the twenty-first century (2071-2100) under scenario RCP8.5.

Figure 6a shows an important aspect of model uncertainties in future projections of summertime climate; across the CMIP5 ensemble, models that are warmer in summer under present-day climate conditions tend to project larger warming in the future over large swaths of the land surface: northern United States and Canada, eastern Europe, central Asia, northern Australia, the Amazon, and parts of sub-Saharan Africa. This positive correlation between present-day simulated temperatures and future projections over land in summer has been noted in the literature (Boberg and Christensen 2012; Christensen and Boberg 2012; Cheruy et al. 2014). The contrast between the sign of this relationship over land and over ocean is also noteworthy; in contrast to continents, over oceans warmer models in the present appear to warm less in the future. Here we focus on temperature changes over land. Figure $6 \mathrm{~b}$ shows a similar correlation, but using future warming amplification patterns (relative to the model mean) instead of absolute warming; that is, over each pixel, for each model separately, mean global warming is subtracted from local warming over that particular pixel. In other words, we correlate present-day climate with the future local amplification of warming compared to mean model warming, thereby controlling for differences in climate sensitivity across models. Positive correlations over land appear more clearly in Fig. 6b, in particular in the tropics. In addition, negative correlations over oceans largely disappear. This suggests that local warming over oceans is largely governed by the same large-scale processes that are associated with model climate sensitivity; over land in the tropics, on the other hand, warming 

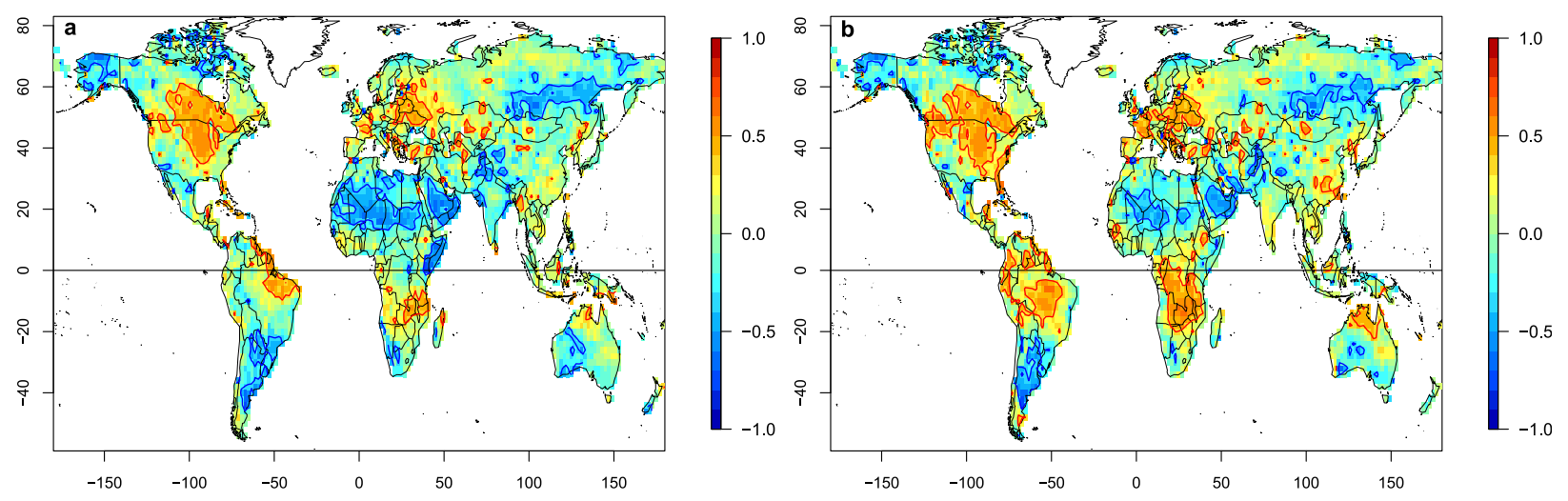

FIG. 7. Correlation across 32 models between mean present-day (1950-2005) SM-ET coupling and, respectively, (a) projected summertime warming and (b) projected local summertime warming amplification. Contour lines indicate correlations significant at the $5 \%$ level.

patterns are more strongly influenced by local processes, although the different amounts of (absolute) warming across models remain more closely governed by largescale processes.

Figure 7a shows that the intermodel spread in presentday simulated SM-ET coupling is positively correlated with near-surface summertime warming projected by the different models over parts of the land surface in the midlatitudes (Europe and central United States and Canada) and in parts of the tropics. Models that are more strongly soil moisture limited in the present tend to project greater warming. Figure $7 \mathrm{~b}$ shows that the relationship in the tropics also becomes clearer when considering the correlation between SM-ET coupling and local warming amplification, instead of absolute warming; models that are strongly soil moisture limited in the present show greater local warming amplification compared to global mean warming (for a given model), while differences in absolute levels of warming between models do not appear strongly associated with soil moisture-related processes.

The spatial correspondence between Figs. 6 and 7 suggests that SM-ET coupling at least partly underlies the relationship between present-day temperatures and future summertime warming over land in CMIP5 models. Focusing here on local warming amplification, Figs. $8 \mathrm{a}$ and $8 \mathrm{~b}$ show that future continental warming amplification projected by the different CMIP5 models is strongly tied to projected changes in incoming solar radiation (governed by changes in cloud cover) and changes in ET. Models that project the greatest increases in solar radiation and smallest (or most negative) changes in ET tend to warm the most, as both factors are associated with increased near-surface temperatures (Cheruy et al. 2014). In turn, Fig. 9 shows that projected changes in incoming solar radiation and ET appear constrained by present-day simulated SM-ET coupling across models. Over parts of North America and
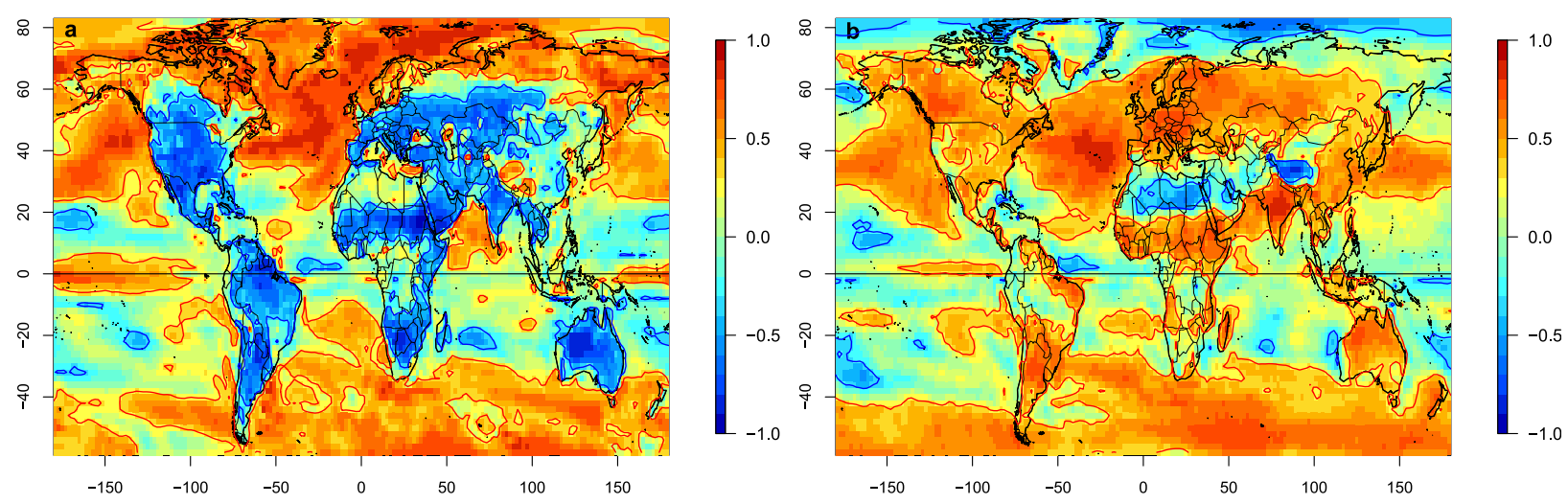

FIG. 8. Correlation across 40 models between projected local summertime warming amplification and, respectively, (a) projected summertime change in ET and (b) projected summertime change in incoming solar radiation at the surface. Contour lines indicate correlations significant at the $5 \%$ level. 

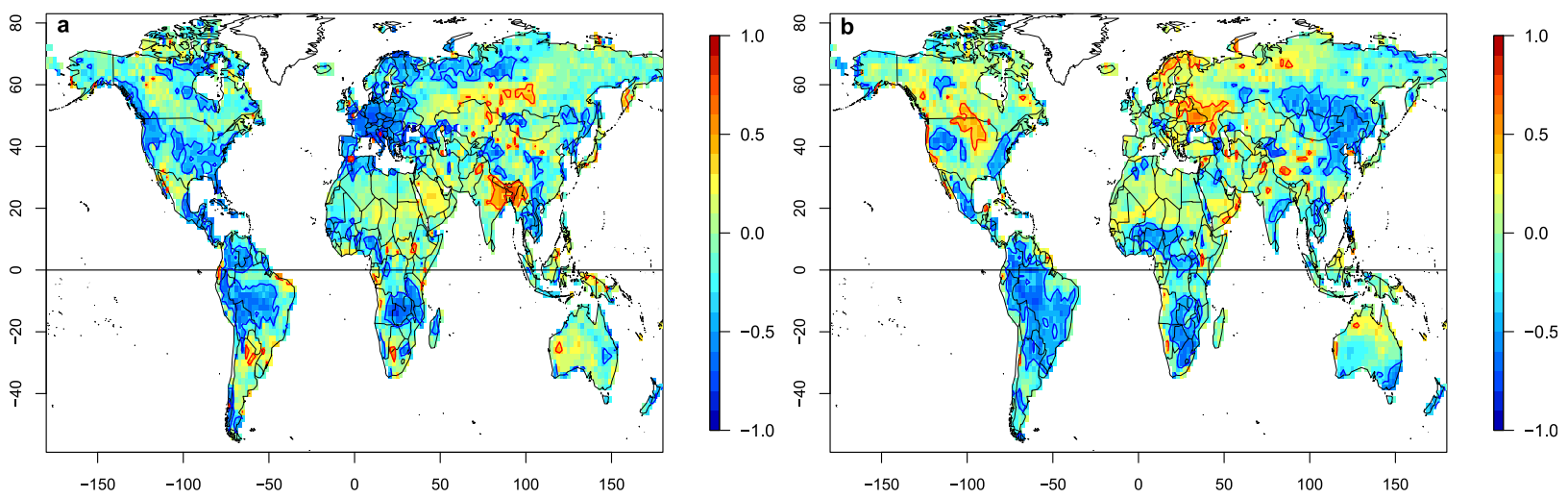

FIG. 9. Correlation across 32 models between mean present-day (1950-2005) SM-ET coupling and, respectively, (a) projected summertime change in ET and (b) projected summertime change in incoming solar radiation at the surface. Contour lines indicate correlations significant at the $5 \%$ level.

Europe, models with stronger present-day SM-ET coupling project smaller (or more negative) changes in ET, as well as greater increases in incoming solar radiation. In other words, models that are more strongly soil moisture limited in summer in the present tend to become warmer and drier in the future, with reduced ET, greater sunshine, and reduced cloud cover and precipitation (not shown). In the tropics, greater SM-ET coupling in the present is associated with greater projected local warming amplification (compared to the global mean) over parts of the Amazon, tropical Africa, and northern Australia. In these regions as well, greater present-day soil moisture limitation is associated with smaller (or more negative) ET changes, which is consistent with greater (local) warming. However, in contrast to midlatitude regions, over tropical regions concurrent changes in incoming solar radiation, across models, are negatively correlated with present-day simulated SM-ET coupling. Indeed, over the tropics changes in incoming solar radiation and ET are positively correlated across models. This could suggest a negative feedback between changes in ET (constrained by present-day SM-ET coupling) and cloud cover, whereby reduced ET and greater sensible heating lead to increased cloud cover and thus reduced incoming solar radiation. However, no clear relationship between changes in summertime-mean ET and cloud cover is evident across models in these regions (not shown). Changes at the intraseasonal time scale, unexamined here, might play a role in the relationship between ET and cloud cover/radiation changes.

To the extent that models with greater present-day SM-ET coupling project greater future warming (Figs. 8 and 9), and that they are also associated with a warmer and drier simulated climate in the present (section 4c), differences in SM-ET coupling between models contribute to the relationship shown on Fig. 6 between present-day temperatures and future (local) warming over land in summer.

\section{Discussion and conclusions}

In this study we have analyzed the diversity of SM-ET coupling between CMIP5 models and its relationship with characteristics of the present-day summertime climate simulated in these models, as well as with aspects of their projections of future warming. To characterize the coupling between soil moisture and ET, we have used a simple correlation at the interannual time scale between summertime-mean surface soil moisture and ET. As indicated in section 2, this remains a simple, firstorder quantification of soil moisture's impact on surface fluxes, compared to more refined metrics focusing on shorter time scale land behavior, such as the rate of nearsurface warming compared to surface skin warming during dry spells (e.g., Gallego-Elvira et al. 2016). However, it has the advantage of being easily calculable across models. As discussed in section 2, other metrics focus on the slope of the regression between soil moisture and ET (e.g., Dirmeyer 2011b). Figure 10 shows that the multimodel-mean pattern of that sensitivity (i.e., the slope of the regression) is similar to that of the correlation, but the pattern of the intermodel spread is different; uncertainty in the slope of the regression is greater in dry regions. That is, in dry regions, models agree that most of the variance of ET is explained by soil moisture variability; however, the slope of that relationship differs between models. We chose to focus here on the share of explained variance rather than the sensitivity, arguing that it better represents the strength of the relationship between SM and ET. In any case, Fig. 10c also shows that the value of the regression slope 

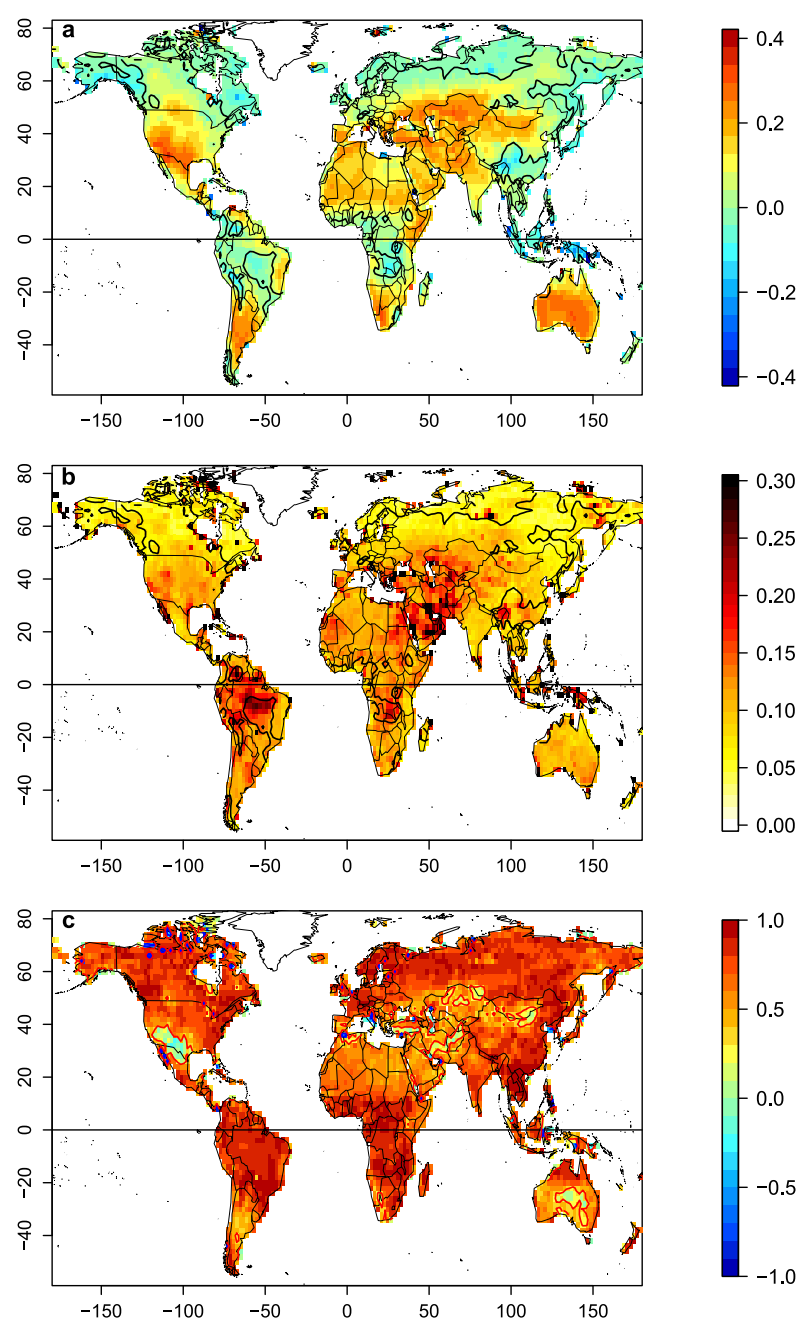

FIG. 10. (a) Multimodel mean (over 37 models) regression coefficient (i.e., slope) between summertime-mean surface SM and ET over 1950-2005 [mm day ${ }^{-1}\left(\mathrm{~kg} \mathrm{~m}^{-2}\right)^{-1}$ ]; black contour indicates the zero line. (b) Standard deviation across CMIP5 models of the regression coefficient between summertime-mean surface SM and ET over 1950-2005; black contour indicates the zero line from (a). (c) Correlations across 37 models between SM-ET coupling (i.e., correlation) and SM-ET regression slope.

and the correlation actually remain strongly correlated over much of the land surface, including over regions of larger spread in SM-ET correlation where our analysis has been focused.

To investigate the relationship between SM-ET coupling and simulated climate as well as future projections in CMIP5 models, we have used pixelwise correlations across models between SM-ET coupling and different simulated variables or associated projected changes. Correlation does not necessarily imply causation, but rather simply association between different quantities. We draw on our understanding of physical processes and their impact to infer causation. Isolating the role of

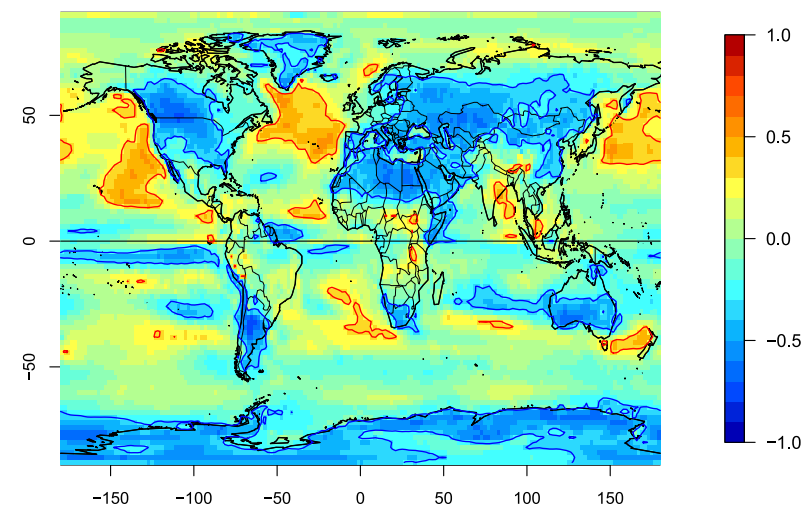

FIG. 11. Correlation across 38 models between summertime cloud cover (mean over 1950-2005) and future projected summertime warming. Contour lines indicate correlations significant at the $5 \%$ level.

different processes on simulated climate and/or projections in models is probably best achieved by targeted perturbedphysics or mechanism-denial experiments. Here, the interpretation of the relationships we diagnose across CMIP5 models is consistent with some of such process studies, for instance regarding the role of land-atmosphere interactions in locally amplifying climate variability, mean temperature, and future warming (e.g., Berg et al. 2014; Lorenz et al. 2016; Vogel et al. 2017). In that sense, we are using the CMIP5 ensemble as a complementary tool to investigate similar processes as in these idealized experiments, extending their results across a wider range of models. We also note that correlation between changes across models does not imply, even in the case of direct causation, that one variable is the main process causing the overall change in the other; rather, simply that it explains model spread. For instance, future changes in ET might explain some of the spread in changes in near-surface warming over land, but the increase in temperature over land across all models is itself first caused by the enhanced greenhouse effect in climate change scenarios.

Our analysis shows that models that, in the midlatitudes, are more strongly soil moisture limited also appear to warm more in their future projections. As discussed in section 3b, part of the model spread in SM-ET coupling is likely linked to differences in model treatment of land hydrology, including differences in the simulation of vegetation and the representation of soil water stress (transpiration being the dominant component of ET globally); however, a significant share of the model spread simply reflects differences in precipitation in the first place. Thus, models that are warmer and drier in those regions in the present tend to become even warmer and drier in the future. The link between projected surface warming and initial soil moisture and radiation conditions is perhaps best illustrated in Fig. 11, 
which shows the correlation across models between projected changes in near-surface temperature and present-day simulated cloud cover. Cloud cover, because of its association with precipitation on the one hand (and thus moisture availability) and incoming solar radiation on the other, arguably captures differences in moisture and radiative conditions across models. Figure 11 shows that over land in summer cloud deficit in the present tends to translate to greater warming in the future. Together Figs. 6-11 suggest that model biases in the present in terms of moisture availability and surface radiation will affect projections of near-surface warming. Indeed, it has been shown that present-day CMIP5 models show common warm biases over parts of North America and Europe (Cheruy et al. 2014). These regions also correspond to regions identified on Fig. 4 as too dry and potentially too strongly soil moisture limited. This reinforces concerns that projections over these regions might be overestimated toward dry and warm conditions in the future, with low ET, high radiation, and high temperatures (Boberg and Christensen 2012; Cheruy et al. 2014; Herrera-Estrada and Sheffield 2017). Previous studies have sought to link model biases in the present with their projections for the future; one of the earliest studies (Shukla et al.2006) found that models with the greatest fidelity in simulating seasonal mean air temperature during the twentieth century are the ones that project the most warming in the future. Focusing here on continental midlatitudes and in summer specifically, the relationship we find appears opposite; over these regions, models with greater dry and warm present-day biases in summer tend to produce overly dry and warm projections for the future, in part, as we have shown, because of the role of land-atmosphere processes.

Understanding the relationship between present-day climate biases and future projections, as well as identifying the particular processes underlying this relationship, should be useful to model developers and to those seeking to understand model biases and their implications, and ultimately to reduce such biases. It also suggests that, in the current state of model uncertainties, efforts to constrain future projections by evaluating climate models against observations of present-day land-atmosphere coupling, where available (Sippel et al. 2017), or, more generally, of present-day climate, can offer avenues to reduce uncertainties in climate model projections of future summertime continental warming.

Acknowledgments. This work was supported by NOAA Grant NA15OAR4310091.

\section{REFERENCES}

Berg, A., B. R. Lintner, K. L. Findell, S. Malyshev, P. C. Loikith, and P. Gentine, 2014: Impact of soil moisture-atmosphere interactions on surface temperature distribution. J. Climate, 27, 7976-7993, https://doi.org/10.1175/JCLI-D-13-00591.1.

_ , and Coauthors, 2015: Interannual coupling between summertime surface temperature and precipitation over land: Processes and implications for climate change. J. Climate, 28, 1308-1328, https://doi.org/10.1175/JCLI-D-14-00324.1.

-, and Coauthors, 2016: Land-atmosphere feedbacks amplify aridity increase over land under global warming. Nat. Climate Change, 6, 869-874, https://doi.org/10.1038/nclimate3029.

—, B. R. Lintner, K. L. Findell, and A. Giannini, 2017a: Soil moisture influence on seasonality and large-scale circulation in simulations of the West African monsoon. J. Climate, 30, 2295-2317, https://doi.org/10.1175/JCLI-D-15-0877.1.

— - J. Sheffield, and P. C. D. Milly, 2017b: Divergent surface and total soil moisture projections under global warming. Geophys. Res. Lett., 44, 236-244, https://doi.org/10.1002/ 2016GL071921.

Boberg, F., and J. H. Christensen, 2012: Overestimation of Mediterranean summer temperature projections due to model deficiencies. Nat. Climate Change, 2, 433-436, https://doi.org/ 10.1038/nclimate1454.

Cheruy, F., J. L. Dufresne, F. Hourdin, and A. Ducharne, 2014: Role of clouds and land-atmosphere coupling in midlatitude continental summer warm biases and climate change amplification in CMIP5 simulations. Geophys. Res. Lett., 41, 64936500, https://doi.org/10.1002/2014GL061145.

Christensen, J. H., and F. Boberg, 2012: Temperature dependent climate projection deficiencies in CMIP5 models. Geophys. Res. Lett., 39, L24705, https://doi.org/10.1029/2012GL053650.

Cook, B. I., G. B. Bonan, and S. Levis, 2006: Soil moisture feedbacks to precipitation in southern Africa. J. Climate, 19, 41984206, https://doi.org/10.1175/JCLI3856.1.

Dirmeyer, P. A., 2003: The role of the land surface background state in climate predictability. J. Hydrometeor., 4, 599-610, https:// doi.org/10.1175/1525-7541(2003)004<0599:TROTLS>2.0.CO;2.

, 2011a: A history of the Global Soil Wetness Project (GSWP). J. Hydrometeor., 12, 729-749, https://doi.org/10.1175/JHM-D10-05010.1.

2011b: The terrestrial segment of soil moisture-climate coupling. Geophys. Res. Lett., 38, L16702, https://doi.org/ 10.1029/2011GL048268.

, R. D. Koster, and Z. Guo, 2006: Do global models properly represent the feedback between land and atmosphere? J. Hydrometeor., 7, 1177-1198, https://doi.org/10.1175/JHM532.1.

— C. A. Schlosser, and K. L. Brubaker, 2009: Precipitation, recycling, and land memory: An integrated analysis. J. Hydrometeor., 10, 278-288, https://doi.org/10.1175/ 2008JHM1016.1.

, Y. Jin, B. Singh, and X. Yan, 2013a: Trends in land-atmosphere interactions from CMIP5 simulations. J. Hydrometeor., 14, 829849, https://doi.org/10.1175/JHM-D-12-0107.1.

$-, \ldots,-$, and,$- 2013 \mathrm{~b}$ : Evolving land-atmosphere interactions over North America from CMIP5 simulations. J. Climate, 26, 7313-7327, https://doi.org/10.1175/JCLI-D-1200454.1.

Diro, G. T., L. Sushama, A. Martynov, D. I. Jeong, D. Verseghy, and K. Winger, 2014: Land-atmosphere coupling over North America in CRCM5. J. Geophys. Res. Atmos., 119, 1195511 972, https://doi.org/10.1002/2014JD021677. 
Findell, K. L., P. Gentine, B. R. Lintner, and C. Kerr, 2011: Probability of afternoon precipitation in eastern United States and Mexico enhanced by high evaporation. Nat. Geosci., 4, 434-439, https://doi.org/10.1038/ngeo1174.

,,--- , and B. P. Guillod, 2015: Data length requirements for observational estimates of land-atmosphere coupling strength. J. Hydrometeor., 16, 1615-1635, https://doi.org/ 10.1175/JHM-D-14-0131.1.

Fischer, E. M., S. I. Seneviratne, D. Lüthi, and C. Schär, 2007: The contribution of land-atmosphere coupling to recent European summer heatwaves. Geophys. Res. Lett., 34, L06707, https:// doi.org/10.1029/2006GL027992.

Gallego-Elvira, B., C. M. Taylor, P. P. Harris, D. Ghent, K. L. Veal, and S. S. Folwell, 2016: Global observational diagnosis of soil moisture control on the land surface energy balance. Geophys. Res. Lett., 43, 2623-2631, https://doi.org/10.1002/ 2016 GL068178.

Gent, P. R., and Coauthors, 2011: The Community Climate System Model version 4. J. Climate, 24, 4973-4991, https://doi.org/ 10.1175/2011JCLI4083.1.

Guillod, B. P., B. Orlowsky, D. G. Miralles, A. J. Teuling, and S. I. Seneviratne, 2015: Reconciling spatial and temporal soil moisture effects on afternoon rainfall. Nat. Commun., 6, 6443, https://doi.org/10.1038/ncomms7443.

Guo, Z., and Coauthors, 2006: GLACE: The Global LandAtmosphere Coupling Experiment. Part II: Analysis. J. Hydrometeor., 7, 611-625, https://doi.org/10.1175/JHM511.1.

Herrera-Estrada, J. E., and J. Sheffield, 2017: Uncertainties in future projections of summer droughts and heat waves over the contiguous United States. J. Climate, 30, 6225-6246, https:// doi.org/10.1175/JCLI-D-16-0491.1.

Koster, R. D., and Coauthors, 2004: Regions of strong coupling between soil moisture and precipitation. Science, 305, 11381140, https://doi.org/10.1126/science.1100217.

_ , and Coauthors, 2006: GLACE: The Global LandAtmosphere Coupling Experiment. Part I: Overview. J. Hydrometeor., 7, 590-610, https://doi.org/10.1175/JHM510.1.

Langenbrunner, B., J. D. Neelin, B. R. Lintner, and B. T. Anderson, 2015: Patterns of precipitation change and climatological uncertainty among CMIP5 models, with a focus on the midlatitude Pacific storm track. J. Climate, 28, 7857-7872, https://doi.org/ 10.1175/JCLI-D-14-00800.1.

Lawrence, D. M., and J. M. Slingo, 2005: Weak land-atmosphere coupling strength in HadAM3: The role of soil moisture variability. J. Hydrometeor., 6, 670-680, https://doi.org/10.1175/ JHM445.1.

Levine, P. A., J. T. Randerson, S. C. Swenson, and D. M. Lawrence, 2016: Evaluating the strength of the land-atmosphere moisture feedback in Earth system models using satellite observations. Hydrol. Earth Syst. Sci., 20, 4837-4856, https://doi.org/ 10.5194/hess-20-4837-2016.

Lorenz, R., and Coauthors, 2016: Influence of land-atmosphere feedbacks on temperature and precipitation extremes in the GLACE-CMIP5 ensemble. J. Geophys. Res. Atmos., 121, $607-$ 623, https://doi.org/10.1002/2015JD024053.

Orth, R., and S. I. Seneviratne, 2017: Variability of soil moisture and sea surface temperatures similarly important for warm-season land climate in the Community Earth System Model. J. Climate, 30, 2141-2162, https://doi.org/10.1175/JCLI-D-15-0567.1.
Riahi, K., and Coauthors, 2011: RCP 8.5-A scenario of comparatively high greenhouse gas emissions. Climatic Change, 109, 33-57, https://doi.org/10.1007/s10584-011-0149-y.

Sakamoto, T. T., and Coauthors, 2012: MIROC4h-A new highresolution atmosphere-ocean coupled general circulation model. J. Meteor. Soc. Japan, 90, 325-359, https://doi.org/ 10.2151/jmsj.2012-301.

Santanello, J. A., Jr., C. D. Peters-Lidard, S. V. Kumar, C. Alonge, and W.-K. Tao, 2009: A modeling and observational framework for diagnosing local land-atmosphere coupling on diurnal time scales. J. Hydrometeor., 10,577-599, https://doi.org/ 10.1175/2009JHM1066.1.

_., and Coauthors, 2018: Land-atmosphere interactions: The LoCo perspective. Bull. Amer. Meteor. Soc., https://doi.org/ 10.1175/BAMS-D-17-0001.1, in press.

Scheff, J., and D. M. W. Frierson, 2014: Scaling potential evapotranspiration with greenhouse warming. J. Climate, 27, 15391558, https://doi.org/10.1175/JCLI-D-13-00233.1.

Seneviratne, S. I., D. Lüthi, M. Litschi, and C. Schär, 2006: Landatmosphere coupling and climate change in Europe. Nature, 443, 205-209, https://doi.org/10.1038/nature05095.

, T. Corti, E. L. Davin, M. Hirschi, E. B. Jaeger, I. Lehner, B. Orlowsky, and A. J. Teuling, 2010: Investigating soil moisture-climate interactions in a changing climate: A review. Earth-Sci. Rev., 99, 125-161, https://doi.org/10.1016/ j.earscirev.2010.02.004.

_ , and Coauthors, 2013: Impact of soil moisture-climate feedbacks on CMIP5 projections: First results from the GLACECMIP5 experiment. Geophys. Res. Lett., 40, 5212-5217, https://doi.org/10.1002/grl.50956.

Sheffield, J., and Coauthors, 2013: North American climate in CMIP5 experiments. Part I: Evaluation of historical simulations of continental and regional climatology. J. Climate, 26, 9209-9245, https://doi.org/10.1175/JCLI-D-12-00592.1.

Shukla, J., T. DelSole, M. Fennessy, J. Kinter, and D. Paolino, 2006: Climate model fidelity and projections of climate change. Geophys. Res. Lett., 33, L07702, https://doi.org/10.1029/ 2005 GL025579.

Sippel, S., J. Zscheischler, M. D. Mahecha, R. Orth, M. Reichstein, M. Vogel, and S. I. Seneviratne, 2017: Refining multi-model projections of temperature extremes by evaluation against land-atmosphere coupling diagnostics. Earth Syst. Dyn., 8, 387-403, https://doi.org/10.5194/esd-8-387-2017.

Taylor, C. M., R. A. M. de Jeu, F. Guichard, P. P. Harris, and W. A. Dorigo, 2012: Afternoon rain more likely over drier soils. Nature, 489, 423-426, https://doi.org/10.1038/nature11377.

Tuttle, S., and G. Salvucci, 2016: Empirical evidence of contrasting soil moisture-precipitation feedbacks across the United States. Science, 352, 825-828, https://doi.org/10.1126/science.aaa7185.

Vogel, M. M., R. Orth, F. Cheruy, S. Hagemann, R. Lorenz, B. J. J. M. van den Hurk, and S. I. Seneviratne, 2017: Regional amplification of projected changes in extreme temperatures strongly controlled by soil moisture-temperature feedbacks. Geophys. Res. Lett., 44, 1511-1519, https://doi.org/10.1002/ 2016GL071235.

Williams, C. J. R., R. P. Allan, and D. R. Kniveton, 2012: Diagnosing atmosphere-land feedbacks in CMIP5 climate models. Environ. Res. Lett., 7, 044003, https://doi.org/10.1088/ 1748-9326/7/4/044003. 